Check for updates

Cite this: RSC Adv., 2019, 9, 24333

Received 14th June 2019

Accepted 30th July 2019

DOI: 10.1039/c9ra04485j

rsc.li/rsc-advances

\section{Narjatamanins A and B, a pair of novel epimers possessing a 2,3-seco-iridoid skeleton with an unusual 1,10-oxygen bridge from Nardostachys jatamansi and evaluation of their effects on worm paralysis in AD C. elegans $\dagger$}

\author{
Ye Zhao, ${ }^{a}$ Bing Li, ${ }^{a}$ Yi-Fan Yu, ${ }^{a}$ Pei-Qian Wu, ${ }^{a}$ Chun-Xue Yu, ${ }^{a}$ Pan-Jie Su, ${ }^{a}$ \\ De-Juan Zhi, ${ }^{a}$ Feng-Ming Qi, ${ }^{b}$ Dong-Qing Fei ${ }^{* a}$ and Zhan-Xin Zhang (D) *a
}

Narjatamanins A (1) and B (2), a pair of epimers possessing a novel 2,3-seco-iridoid skeleton with an unusual 1,10-oxygen bridge, were isolated from the whole plants of Nardostachys jatamansi. Their structures were elucidated by a combination of various spectroscopic methods, including HRESIMS, IR and 1D and 2D NMR techniques. The absolute configurations of 1 and 2 were established by electronic circular dichroism (ECD) calculations. The pharmacological activities of 1 and 2 to alleviate AD-like symptoms were also evaluated using the Caenorhabditis elegans Alzheimer's disease (AD) pathological model, and narjatamanins A (1) and $B(2)$ showed statistically significant delay in the worm paralysis phenotype of AD-like symptoms.

\section{Introduction}

Nardostachys jatamansi DC, which belongs to the genus Nardostachys (Valerianaceae), is a perennial herb mainly distributed in China and India. ${ }^{1}$ As a traditional medicine, its rhizomes and roots have been widely used as sedatives and analgesic in folk lore. ${ }^{1,2}$ It's worth mentioning that the rhizomes of $N$. jatamansi are also a key ingredient in ayurvedic formulations as an anticonvulsant. ${ }^{3}$ Several biological effects of the extracts from this species were reported, such as stress remedies, nervous headaches, epilepsy, intestinal colic, improving learning and memory and liver protection. ${ }^{4-7}$ Besides, recent studies have showed chemical constituents of $N$. jatamansi possess positive anti-Alzheimer's disease activity. ${ }^{\mathbf{8 , 9}}$ To the best of our knowledge, previous phytochemical investigations on $N$. jatamansi led to the isolation of iridoids, sesquiterpenoids, and lignans. ${ }^{10-13}$ In an attempt to further explore structurally and biologically interesting natural products, ${ }^{\mathbf{1 4 - 1 7}}$ we investigated the chemical constituents of the whole plants of $N$. jatamansi, which has resulted in the isolation and structural characterization of a pair of epimers possessing a novel 2,3-seco-iridoid skeleton with an unusual 1,10-oxygen bridge, named narjatamanins A (1) and B (2) (Fig. 1). In this paper, we describe the

${ }^{a}$ School of Pharmacy, Lanzhou University, Lanzhou 730000, People's Republic of China.E-mail:feidq@lzu.edu.cn; zhangzhx@lzu.edu.cn

${ }^{b}$ State Key Laboratory of Applied Organic Chemistry, Lanzhou University, Lanzhou 730000, People's Republic of China

$\dagger$ Electronic supplementary information (ESI) available: NMR, HRESIMS, and IR spectra of compounds 1 and 2. See DOI: 10.1039/c9ra04485j isolation, structural elucidation, and the pharmacological activities of narjatamanins A (1) and B (2) towards alleviating Alzheimer's disease like symptoms in $\mathrm{AD}$ Caenorhabditis elegans.

\section{Results and discussion}

Compound 1 was obtained as a colorless oil. Its molecular formula of $\mathrm{C}_{12} \mathrm{H}_{18} \mathrm{O}_{4}$ was determined by HRESIMS at $\mathrm{m} / \mathrm{z}$ 249.1110 $[\mathrm{M}+\mathrm{Na}]^{+}$(calcd for $\mathrm{C}_{12} \mathrm{H}_{18} \mathrm{O}_{4} \mathrm{Na}$, 249.1097), which required four degrees of unsaturation. Its IR spectrum revealed absorption bands for hydroxyl $\left(3445 \mathrm{~cm}^{-1}\right)$, double bond $\left(1625 \mathrm{~cm}^{-1}\right)$, and aldehyde carbonyl $\left(1690 \mathrm{~cm}^{-1}\right)$ groups. Its ${ }^{1} \mathrm{H}$ NMR spectroscopic data (Table 1) showed one oxygenated methine $\left[\delta_{\mathrm{H}} 4.01(1 \mathrm{H}, \mathrm{m})\right]$, one acetal methine $\left[\delta_{\mathrm{H}} 5.03(1 \mathrm{H}, \mathrm{d}, J\right.$ $=4.8 \mathrm{~Hz})]$, an aldehyde proton $\left[\delta_{\mathrm{H}} 9.58(1 \mathrm{H}, \mathrm{s})\right]$, one ethoxyl group $\left[\delta_{\mathrm{H}} 3.89(1 \mathrm{H}, \mathrm{m}), 3.62(1 \mathrm{H}, \mathrm{m})\right.$, and $1.27(3 \mathrm{H}, \mathrm{t}, J=7.2$

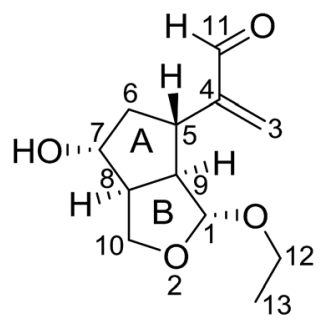

1<smiles>[Z2]CO[14C]1(OCC)OC[C@H]2[C@@H](O)C[C@H](C(=C)C=O)[C@H]21</smiles>

2
Fig. 1 Structures of narjatamanins A (1) and B (2). 
Table $1{ }^{1} \mathrm{H}(600 \mathrm{MHz})$ and ${ }^{13} \mathrm{C}(150 \mathrm{MHz})$ NMR data of compounds 1 and 2 in $\mathrm{CDCl}_{3}$ ( $\delta$ in ppm)

\begin{tabular}{|c|c|c|c|c|}
\hline \multirow[b]{2}{*}{ Position } & \multicolumn{2}{|l|}{1} & \multicolumn{2}{|l|}{2} \\
\hline & $\delta_{\mathrm{H}}(J$ in $\mathrm{Hz})$ & $\delta_{\mathrm{C}}$ & $\delta_{\mathrm{H}}(J$ in $\mathrm{Hz})$ & $\delta_{\mathrm{C}}$ \\
\hline 1 & $5.03(\mathrm{~d}, 4.8)$ & 101.5 & 5.06 (brs) & 108.1 \\
\hline 3 & $\begin{array}{l}6.01(\mathrm{brs}) \\
6.28(\mathrm{brs})\end{array}$ & 132.8 & $\begin{array}{l}6.07 \text { (brs) } \\
6.34 \text { (brs) }\end{array}$ & 133.5 \\
\hline 4 & & 152.9 & & 151.8 \\
\hline 5 & $3.29(\mathrm{~m})$ & 34.2 & $2.95(\mathrm{~m})$ & 39.2 \\
\hline $6 \alpha$ & $2.01(\mathrm{~m})$ & 43.9 & $1.76(\mathrm{~m})$ & 40.6 \\
\hline $6 \beta$ & $2.19(\mathrm{~m})$ & & $1.95(\mathrm{~m})$ & \\
\hline 7 & $4.01(\mathrm{~m})$ & 72.1 & $4.29(\mathrm{~m})$ & 72.9 \\
\hline 8 & $2.96(\mathrm{~m})$ & 48.7 & $2.90(\mathrm{~m})$ & 47.5 \\
\hline 9 & $2.56(\mathrm{~m})$ & 54.9 & $2.52(\mathrm{~m})$ & 55.6 \\
\hline $10 \alpha$ & $3.92(\mathrm{t}, 9.0)$ & 64.6 & $3.84(\mathrm{t}, 8.4)$ & 65.2 \\
\hline $10 \beta$ & $4.04(\mathrm{~m})$ & & $4.20(\mathrm{~d}, 9.0)$ & \\
\hline 11 & $9.58(\mathrm{~s})$ & 194.7 & $9.57(\mathrm{~s})$ & 194.3 \\
\hline \multirow[t]{2}{*}{12} & $3.89(\mathrm{~m})$ & 62.7 & $3.43(\mathrm{~m})$ & 62.3 \\
\hline & $3.62(\mathrm{~m})$ & & $3.66(\mathrm{~m})$ & \\
\hline 13 & $1.27(\mathrm{t}, 7.2)$ & 14.8 & $1.17(\mathrm{t}, 7.2)$ & 14.9 \\
\hline $7-\mathrm{OH}$ & 4.03 (brs) & & 2.58 (brs) & \\
\hline
\end{tabular}

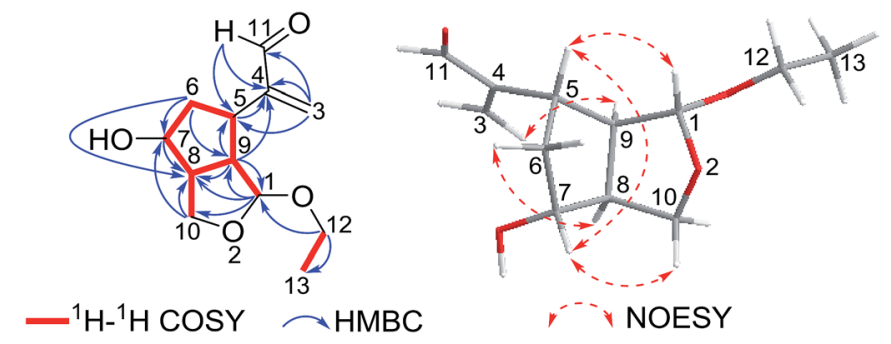

Fig. 2 Key ${ }^{1} \mathrm{H}-{ }^{1} \mathrm{H}$ COSY, HMBC and NOESY correlations of 1.

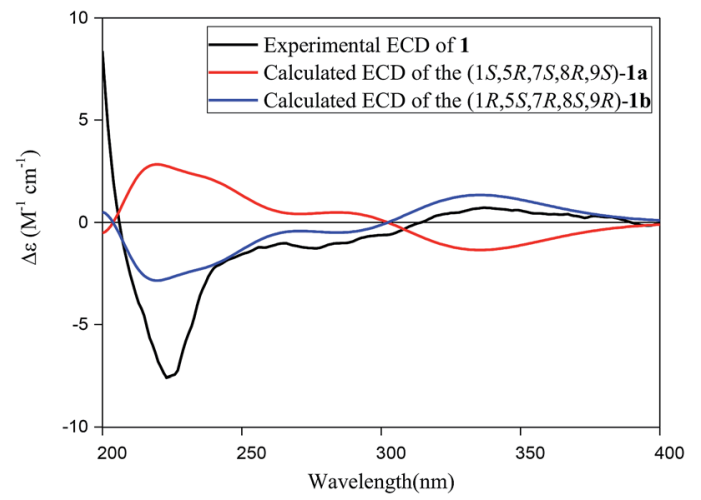

Fig. 3 Calculated and experimental ECD spectra of 1.

$\mathrm{Hz})]$. Furthermore, a pair of isolated $\mathrm{AB}$ protons $\left[\delta_{\mathrm{H}} 6.01(1 \mathrm{H}\right.$, brs) and $6.28(1 \mathrm{H}, \mathrm{brs})]$ indicated the presence of a terminal double bond. The ${ }^{13} \mathrm{C}$ NMR (Table 1) and DEPT spectra of 1 exhibited 12 carbon signals, which were sorted into one methyl, four methylenes (including two oxygenated carbons and one olefinic carbon), six methines (including one acetal carbon, one oxygenated carbon, and one aldehyde carbonyl carbon). Two degrees of unsaturation represent one double bond and one aldehyde group, and the remaining two degrees of unsaturation pointed to two ring systems for compound 1.

Interpretation of the $2 \mathrm{D}$ NMR data, containing ${ }^{1} \mathrm{H}-{ }^{1} \mathrm{H}$ COSY, HSQC, and HMBC spectra, led to the construction of the planar structure of $\mathbf{1}$ (Fig. 2). The ${ }^{1} \mathrm{H}-{ }^{1} \mathrm{H}$ COSY revealed the presence of two structural fragments $\left[\mathrm{CH}(1)-\mathrm{CH}(9)-\mathrm{CH}(8) / \mathrm{CH}(5)-\mathrm{CH}_{2}(6)-\right.$ $\mathrm{CH}(7)-\mathrm{CH}(8)-\mathrm{CH}_{2}(10)$ and $\left.\mathrm{CH}_{2}(12)-\mathrm{CH}_{3}(13)\right]$, which demonstrated the presence of a cyclopentane moiety (ring A). Given that $\mathrm{C}-1$ and $\mathrm{C}-10$ (one acetal methine carbon and one oxygenated methylene carbon, $\delta_{\mathrm{C}} 101.5$ and 64.6) were dramatically shifted downfield compared to typical hydroxylated carbons, an epoxy group was proposed between C-1 and C-10. Moreover, the HMBC correlations from acetal proton $\mathrm{H}-1$ to $\mathrm{C}-8, \mathrm{C}-9$ and C-10, from $\mathrm{H}_{2}-10$ to $\mathrm{C}-7$ and $\mathrm{C}-8$, from $\mathrm{H}-9$ to $\mathrm{C}-1, \mathrm{C}-5$ and $\mathrm{C}-8$ demonstrated the presence of a tetrahydrofuran ring (ring $\mathrm{B}$ ) moiety fused to a cyclopentane (ring A) at C-8 and C-9. Other HMBC correlations from olefinic protons $\mathrm{H}_{2}-3$ to C-4, C-5 and C11, from aldehyde proton $\mathrm{H}-11$ to $\mathrm{C}-4$ and $\mathrm{C}-5$ indicated the existence of an acrolein moiety that was located at C-5. Finally, the location of the ethoxyl group at C-1 was implied by the HMBC cross peaks of $\mathrm{H}_{2}-12$ with $\mathrm{C}-1$ and C-13. Considering the molecular formula, the downfield chemical shift of C-7 $\left(\delta_{\mathrm{C}} 72.1\right)$ suggested a hydroxyl group suited at $\mathrm{C}-7$, which could be proposed to share the remaining one oxygen atom. Thus, the planar structure of 1 was confirmed to be a novel 2,3-seco-iridoid with an oxygen bridge connecting $\mathrm{C}-1$ and $\mathrm{C}-10$.

The relative stereochemistry of compound $\mathbf{1}$ was resolved by NOESY spectrum as well as a computer-generated lower energy conformation using MM2 force field calculations (Fig. 2). The NOESY correlations of $\mathrm{H}-7 / \mathrm{H}-10 \beta, \mathrm{H}-7 / \mathrm{H}-5$, and $\mathrm{H}-5 / \mathrm{H}-1$ indicated that $\mathrm{H}-1, \mathrm{H}-5, \mathrm{H}-10 \beta$ and $\mathrm{H}-7$ were cofacial and randomly assigned as $\beta$-orientation. The NOESY correlations of $\mathrm{H}-9 / \mathrm{H}-3 \mathrm{a}$, $\mathrm{H}-8 / \mathrm{H}-6 \alpha$ combined with the unobserved correlations of $\mathrm{H}-8 / \mathrm{H}-$ 5 and $\mathrm{H}-8 / \mathrm{H}-1$ revealed that $\mathrm{H}-9, \mathrm{H}-6 \alpha$ and $\mathrm{H}-8$ were in the same orientation and assigned as $\alpha$-orientation.

The absolute configuration of $\mathbf{1}$ was established by comparison of its experimental electronic circular dichroism (ECD) spectrum with calculated the computational spectra of the $(1 S, 5 R, 7 S, 8 R, 9 S)-\mathbf{1 a}$ and $(1 R, 5 S, 7 R, 8 S, 9 R)-\mathbf{1 b}$ using the timedependent density functional theory (TD-DFT) method. As shown in Fig. 3, spectrum calculated for the $(1 R, 5 S, 7 R, 8 S, 9 R)-\mathbf{1 b}$ was nearly identical with the experimental data of 1 over the whole range of wavelengths under investigation, which confirmed the assignment of the absolute configuration of $\mathbf{1}$ as $1 R, 5 S, 7 R, 8 S$ and $9 R$. Thus, the absolute configuration of compound 1 could be defined unequivocally as shown in Fig. 1, and it was given the trivial name of narjatamanin A.

Compound 2 was obtained as a colorless oil. The HRESIMS indicated a molecule formula of $\mathrm{C}_{12} \mathrm{H}_{18} \mathrm{O}_{4}(\mathrm{~m} / \mathrm{z} 249.1098$, calcd for $\left.\mathrm{C}_{12} \mathrm{H}_{18} \mathrm{O}_{4} \mathrm{Na}, 249.1097\right)$, the same as that of 1. After the analysis of their ${ }^{1} \mathrm{H}$ and ${ }^{13} \mathrm{C}$ NMR data, compound 2 was found to share the same planar structure with compound 1. Furtherly, the planar structure of compound 2 was confirmed by 2D NMR, including HSQC, ${ }^{1} \mathrm{H}-{ }^{1} \mathrm{H}$ COSY, and HMBC spectra. In comparison of their ${ }^{1} \mathrm{H}-\mathrm{NMR}$, the most remarkable change was the downfield shift of 0.28 ppm for $\mathrm{H}-7$ in 2 which suggested the 


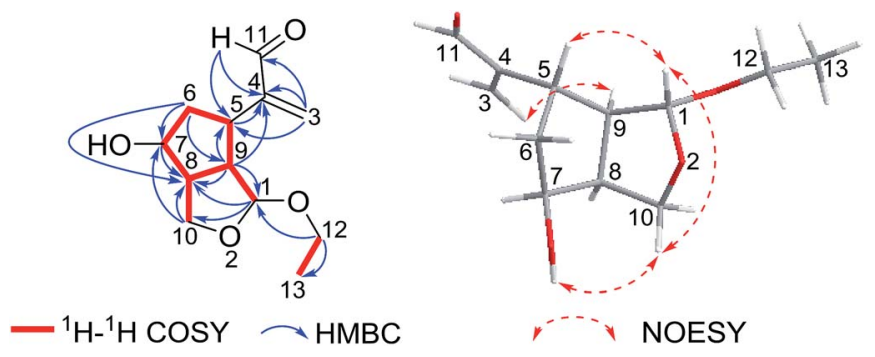

Fig. 4 Key ${ }^{1} \mathrm{H}-{ }^{1} \mathrm{H}$ COSY, HMBC and NOESY correlations of 2.

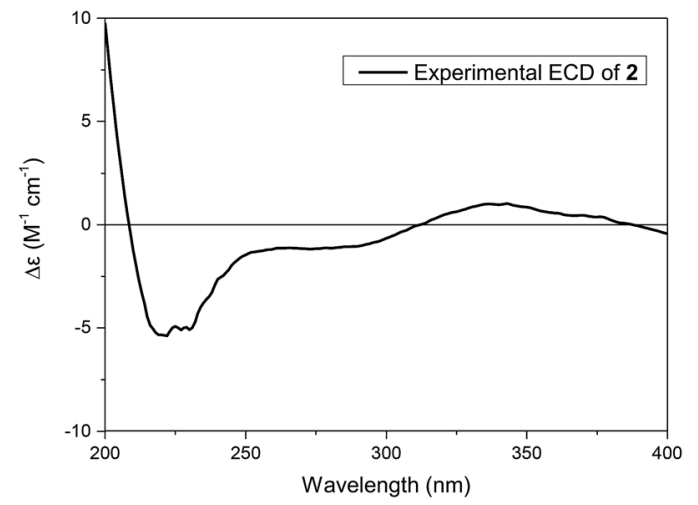

Fig. 5 Experimental ECD spectrum of 2.

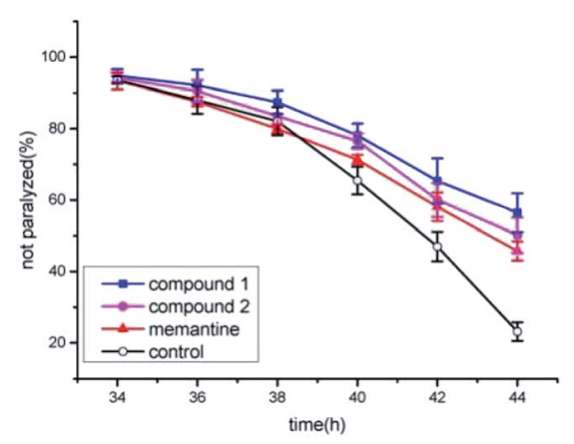

Fig. 6 Anti-Alzheimer's disease (AD) activities of compound 1 and 2 positive control and blank control.

configuration at C-7 could be different with compound $\mathbf{1}$. The relative configuration was ensured by NOESY examination. The NOESY correlations of $\mathrm{H}-1 / \mathrm{H}-10 \beta, \mathrm{H}-10 \beta / \mathrm{OH}-7$, and $\mathrm{H}-1 / \mathrm{H}-5$ implied that $\mathrm{H}-1, \mathrm{H}-5$ and $\mathrm{OH}-7$ were cofacial with $\beta$-oriented. The NOESY correlation of $\mathrm{H}-9 / \mathrm{H}-3 \mathrm{a}$ indicated that $\mathrm{H}-9$ and $\mathrm{H}-5$ were adverse direction, and $\mathrm{H}-9$ was settled as $\alpha$-orientation. Finally, $\mathrm{H}-8$ was determined as $\alpha$-oriented on the basis of the analysis that unobserved NOESY correlations of $\mathrm{H}-8 / \mathrm{H}-5$ and $\mathrm{H}-$ 8/H-1 (Fig. 4).

The absolute configuration of 2 was established by its experimental electronic circular dichroism (ECD) spectrum. The electronic circular dichroism (ECD) curve of 2 showed a negative Cotton effect at $219 \mathrm{~nm}$ and a positive Cotton effect at $343 \mathrm{~nm}$, ascribed to the $\pi-\pi^{*}$ transition and $\mathrm{n}-\pi^{*}$ transition of $\alpha, \beta$-unsaturated ketone, respectively. Furtherly, the positive Cotton effect at $343 \mathrm{~nm}$ in its ECD spectrum (Fig. 5) was same as the positive Cotton effect at $337 \mathrm{~nm}$ in the ECD spectrum of $\mathbf{1}$, which suggested the same configurations of the chiral center adjacent aldehyde carbonyl of $\mathbf{2}$ as $\mathbf{1}$. Thus, the assignment of the absolute configuration of 2 as $1 R, 5 S, 7 S, 8 S$, and $9 R$, and 2 was given the trivial name of narjatamanin $\mathrm{B}$.

Previous works have showed that the effects of compounds tested were linked to their anti-amyloidogenic activity which have been indicated by a readout of worm paralysis being delayed, ${ }^{18,19}$ and the pharmacological actions of compounds tested has been correlated with in vivo amyloid aggregation and toxicity by using transgenic AD worms. ${ }^{20,21}$ Transgenic $\mathrm{AD}$ Caenorhabditis elegans CL4176 was used to evaluate whether new compounds of narjatamanins A (1) and B (2) have pharmacological activities for fighting against $\mathrm{AD}$ worm paralysis. The worms had been transferred with a human $A \beta_{1-42}$ gene downstream of promoter myo-3, and the overexpression of $A \beta_{1-42}$ in worm muscular tissues under nonpermissive condition will lead to the AD like symptom of paralysis phenotype. Previous work has demonstrated that memantine can significantly delay worms paralysis and acts as a disease modifying agent. ${ }^{22} \mathrm{Here}$, memantine was used as positive control. The result showed that $50 \mu \mathrm{M}$ of memantine significantly delayed AD worm paralysis (Fig. 6). Further, $100 \mu \mathrm{M}$ of narjatamanins A (1) and B (2) were also significantly alleviated $\mathrm{AD}$ like symptoms $(p<0.05)$. In contrast to $50 \mu \mathrm{M}$ of memantine, the tested compounds 1 and 2 tended to have a higher pharmacological activity of delaying AD worm paralysis $(p<0.05)$. Additionally, as the hallmark of $\mathrm{AD}$ is amyloid $\beta$ accumulation, and it is widely accepted to be the centre of $\mathrm{AD}$ pathology. ${ }^{20}$ Taken together, our results provided clues that the compounds tested may be potential to be served as anti-AD agents. To study AChE enzyme, radicals scavenging activity and to perform amyloid $\beta$ protein assay will give us the whole anti-AD activity profile of the compounds tested here, we will perform these experiment in our further research.

\section{Conclusion}

In summary, this work discovered a pair of novel epimers named narjatamanins A (1) and B (2) from $N$. jatamansi. These two compounds possessed a novel 2,3-seco-iridoid skeleton with an unprecedented oxygen bridge, which is a structural feature not previously reported in natural products. Their structures were determined by their spectroscopic data. They possessed multiple chiral centers, which could attract great interest from organic synthetic chemists. These two compounds showed statistically significant pharmacological activity of delaying $\mathrm{AD}$ worm paralysis, indicating that they might be potential to act as anti-AD agent candidate.

\section{Experimental section}

\subsection{General experimental procedures}

Optical rotations were determined on a PerkinElmer 341 polarimeter. IR spectra were recorded with a Nicolet NEXUS 670 FT-IR spectrometer in $\mathrm{KBr} .1 \mathrm{D}\left({ }^{1} \mathrm{H},{ }^{13} \mathrm{C}\right.$, DEPT $)$ NMR and 2D 
$\left({ }^{1} \mathrm{H}-{ }^{1} \mathrm{H}\right.$ COSY, HSQC, HMBC, NOESY) NMR were recorded with a Varian INOVA-600 and a Bruker AVANCE NEO-600 spectrometer with TMS as an internal standard. HRESIMS spectra were obtained on a Thermo LTQ Orbitrap Elite mass spectrometer. ECD spectra were recorded on a JASCO J-810 spectrophotometer using $\mathrm{MeOH}$ as the solvent. Silica gel (200-300 mesh) used for column chromatography (CC) and silica gel $\mathrm{GF}_{254}(10-40 \mu \mathrm{m})$ used for thin layer chromatography (TLC) were purchased from the Qingdao Marine Chemical Factory in China. Sephadex LH20 was supplied by GE Healthcare Bio-Sciences AB. MCI GEL CHP 20P (75-150 $\mu \mathrm{m})$ was purchased from Mitsubishi Chemical Holdings in Japan.

\subsection{Plant material}

The whole plants of $N$. jatamansi were collected in Lijiang, Yunnan province, in August of 2017. The plant material was identified by Dr Jian-Yin Li, School of Pharmacy, Lanzhou University. A voucher specimen (no. 201708NJ) was deposited at School of Pharmacy, Lanzhou University, China.

\subsection{Extraction and isolated}

The air-dried and milled whole plants of $N$. jatamansi $(10 \mathrm{~kg})$ were extracted with $95 \% \mathrm{EtOH}$ three times at room temperature to give a crude extract $(1.8 \mathrm{~kg})$. The extract was suspended in $\mathrm{H}_{2} \mathrm{O}$ and partitioned with EtOAc. The EtOAc extract $(890 \mathrm{~g})$ was applied to column chromatography over silica gel eluted with petroleum ether-acetone (from $40: 1$ to $1: 1$ ) gradient elution to obtain six fractions (Fr.1-Fr.6). Fr.3 (71 g) was chromatographed using MCI gel CC eluted with $\mathrm{EtOH}-\mathrm{H}_{2} \mathrm{O}$ gradient $(30 \%, 50 \%, 70 \%, 90 \%, 100 \%, v / v)$ to get five subfractions (Fr.3.1-Fr.3.5). Fr.3.2 was purified by thin layer chromatography (TLC) with $\mathrm{CH}_{2} \mathrm{Cl}_{2}$-acetone $(20: 1)$ to afford compound 1 (8 $\mathrm{mg})$. Fraction 5 was separated to a Sephadex $\mathrm{LH}-20 \mathrm{CC}\left(\mathrm{CHCl}_{3}{ }^{-}\right.$ $\mathrm{CH}_{3} \mathrm{OH}, 1: 1$ ) to give six subfractions (Fr.5.1-Fr.5.6). Fr.5.2 was separated by silica gel $\left(\mathrm{CH}_{2} \mathrm{Cl}_{2}\right.$-acetone, $40: 1$ to $\left.2: 1\right)$ to afford five subfractions (Fr.5.2.1-Fr.5.2.5). Fr.5.2.3 was purified by TLC to yield compound $2(11 \mathrm{mg})$.

Narjatamanin A (1). Colorless oil; $[\alpha]_{\mathrm{D}}^{25}-55\left(c 0.60, \mathrm{CH}_{2} \mathrm{Cl}_{2}\right)$; IR (KBr) $\nu_{\max } 3445,3056,2947,1690,1625,1272,1097$, $735 \mathrm{~cm}^{-1} ;{ }^{1} \mathrm{H}$ and ${ }^{13} \mathrm{C}$ NMR data, see Table 1; HRESIMS $\mathrm{m} / \mathrm{z}$ $249.1100[\mathrm{M}+\mathrm{Na}]^{+}$(calcd for $\mathrm{C}_{12} \mathrm{H}_{18} \mathrm{O}_{4} \mathrm{Na}, 249.1097$ ).

Narjatamanin B (2). Colorless oil; $[\alpha]_{\mathrm{D}}^{25}-47\left(c 1.10, \mathrm{CHCl}_{3}\right)$; IR (KBr) $\nu_{\max } 3449,3088,2936,1690,1625,1272,1099$, $735 \mathrm{~cm}^{-1} ;{ }^{1} \mathrm{H}$ and ${ }^{13} \mathrm{C}$ NMR data, see Table 1; HRESIMS $\mathrm{m} / \mathrm{z}$ $249.1098[\mathrm{M}+\mathrm{Na}]^{+}$(calcd for $\mathrm{C}_{12} \mathrm{H}_{18} \mathrm{O}_{4} \mathrm{Na}, 249.1097$ ).

\subsection{Bioactivity assay for delaying the AD like symptom of paralysis phenotype in transgenic Alzheimer's disease $C$. elegans procedure}

The transgenic C. elegans strain CL4176 (smg-1ts [myo-3/A $\beta_{1-42}$ long 3 '-untranslated region (UTR)]) was obtained from Caenorhabditis Genetics Center (CGC) (University of Minnesota, Minneapolis, MN). Worms were cultured at $16{ }^{\circ} \mathrm{C}$ on nematode growth medium (NGM) plates, which were seeded with $E$. coli (OP50) as standard food resource. About 100 synchronized worms at L1 larval stage were transferred onto NGM containing
$50 \mu \mathrm{M}$ tested compound in $0.1 \%$ DMSO, and $0.1 \%$ DMSO was used as negative control. The animals were kept at $16^{\circ} \mathrm{C}$ till they grew into L3 larval stage, then transferred into a $25^{\circ} \mathrm{C}$ incubator for $34 \mathrm{~h}$. Paralyzed worms were counted under a dissecting microscope at $2 \mathrm{~h}$ intervals until all animals did not moved autonomously and got into paralysis. The pharmacological activity was described as the capacity of tested compounds to delay worm paralysis. For pharmacological activity of delaying AD worm paralysis assay, log rank survival test was used to compare the significance among treatments. ${ }^{19}$ The $p$ value at a level of 0.05 or less was considered as statistical significance.

\section{Conflicts of interest}

The authors declare no conflict interest.

\section{Acknowledgements}

We gratefully acknowledge financial support from the National Natural Science Foundation of China (No. 31870324 and No. 31670350), the National Key Research and Development Program of China (No. 2018YFC1706300 and No. 2018YFC1706304), the Natural Science Foundation of Gansu Province, China (No. 17JR5RA201), the Science and Technology Project of Lanzhou City (2018-4-61), and the Fundamental Research Funds for the Central Universities (No. lzujbky-2018k13).

\section{References}

1 L. Q. Qiu, Flora Reipublicae Popularis Sinicae (Zhongguo Zhiwu Zhi), Science Press, Beijing, 1986, vol. 73, pp. 25-26.

2 A. Chatterjee and S. C. Pakrashi, The Treatise on Indian Medicinal Plants, National Institute of Science Communication, New Delhi, 1997, vol. 5, pp. 99-100.

3 A. Chatterjee, B. Basak, M. Saha, U. Dutta, C. Mukhopadhyay, J. Banerji, Y. Konda and Y. Harigaya, J. Nat. Prod., 2000, 63, 1531-1533.

4 H. Joshi and M. Parle, J. Med. Food, 2006, 9, 113-118.

5 A. Ali, Y. Dua, A. W. Siddiqui, S. Sultana and M. R. M. Rafiullah, Pharm. Biol., 2005, 43, 533-539.

6 V. Prabhu, K. S. Karanth and A. Rao, Planta Med., 1994, 60, 114-117.

7 S. Ali, K. A. Ansari, M. A. Jafry, H. Kabeer and G. Diwakar, J. Ethnopharmacol., 2000, 71, 359-363.

8 Q. F. Liu, Y. Jeon, Y. W. Sung, J. H. Lee, H. Jeong, Y. M. Kim, H. S. Yun, Y. W. Chin, S. Jeon, K. S. Cho and B. S. Koo, Biol. Pharm. Bull., 2018, 41, 470-477.

9 P. Q. Wu, Y. F. Yu, Y. Zhao, C. X. Yu, D. J. Zhi, F. M. Qi, D. Q. Fei and Z. X. Zhang, Org. Biomol. Chem., 2018, 16, 9038-9045.

10 A. Bagchi, Y. Oshima and H. Hikino, Tetrahedron, 1990, 46, 1523-1530.

11 K. Rekha, R. R. Rao, R. Pandey, K. R. Prasad, K. S. Babu, J. R. Vangala, S. V. Kalivendi and J. M. Rao, J. Asian Nat. Prod. Res., 2013, 15, 111-116. 
12 R. S. Chauhan, M. K. Kaul, A. Kumar and M. C. Nautiyal, Sci. Hortic., 2008, 117, 78-81.

13 G. Rücker, J. Tautges, M. L. Maheswari and D. B. Saxena, Phytochemistry, 1976, 15, 224.

14 Z. X. Zhang, H. H. Li, D. J. Zhi, P. Q. Wu, Q. L. Hu, Y. F. Yu, Y. Zhao, C. X. Yu and D. Q. Fei, Tetrahedron Lett., 2018, 59, 4028-4030.

15 Z. X. Zhang, P. Q. Wu, H. H. Li, F. M. Qi, D. Q. Fei, Q. L. Hu, Y. H. Liu and X. L. Huang, Org. Biomol. Chem., 2018, 16, 1745-1750.

16 Z. Y. Li, F. M. Qi, D. J. Zhi, Q. L. Hu, Y. H. Liu, Z. X. Zhang and D. Q. Fei, Org. Chem. Front., 2017, 4, 42-46.
17 D. Q. Fei, L. L. Dong, F. M. Qi, G. X. Fan, H. H. Li, Z. Y. Li and Z. X. Zhang, Org. Lett., 2016, 18, 2844-2847.

18 C. D. Link, Proc. Natl. Acad. Sci. U. S. A., 1995, 92, 9368-9372. 19 C. D. Link, Genes, Brain Behav., 2005, 4, 147-156.

20 V. Dostal, C. M. Roberts and C. D. Link, Genetics, 2010, 186, 857-866.

21 L. Diomede, G. Cassata, F. Fiordaliso, M. Salio, D. Ami, A. Natalello, S. M. Doglia, A. De Luigi and M. Salmona, Neurobiol. Dis., 2010, 40, 424-431.

22 P. Martorell, E. Bataller, S. Llopis, N. Gonzalez, B. Álvarez, F. Montón, P. Ortiz, D. Ramón and S. Genovés, PLoS One, 2013, 8, e63283. 